\title{
CONTRIBUTION OF LEAF LIFE SPAN AND NUTRIENT RESORPTION TO MEAN RESIDENCE TIME: ELASTICITY ANALYSIS
}

\author{
Elena Kazakou, ${ }^{1,3}$ Eric Garnier, ${ }^{1}$ and Olivier Gimenez ${ }^{1,2}$ \\ ${ }^{1}$ CNRS, Centre d'Ecologie Fonctionnelle et Evolutive (UMR 5175), 1919 route de Mende, 34293 Montpellier Cedex 5, France \\ ${ }^{2}$ University of St Andrews, The Observatory, Buchanan Gardens, St Andrews, Fife, Scotland KY16 9LZ United Kingdom
}

\begin{abstract}
We tested the relative contribution of leaf life span (LLS) and nutrient resorption efficiency (RE) to nutrient mean residence time (MRT) in plants. To do so, we introduced the use of elasticity analysis, which aims to measure the impact on MRT of a small change in one component, relative to the impact of equal changes in the other element. We also quantified the joint effect of LLS and RE on MRT, which required the calculation of the second derivatives of MRT with respect to LLS and RE.

The estimation of the first derivatives showed that, although MRT increases linearly with LLS for a given value of RE, the relative effect of RE on MRT elasticity varies according to RE values; when RE $>0.5$, the MRT's elasticity increases exponentially. The calculation of the second derivatives confirmed the importance of RE on MRT's variation.

We used the results of the elasticity analysis to analyze how MRT responded to variation in LLS and nitrogen RE on MRT at the intra- and interspecific levels. For this, we used 18 plant species from three stages of a Mediterranean old-field succession, grown in a common garden experiment at two levels of nitrogen supply.
\end{abstract}

Key words: elasticity; first and second derivatives; inter- and intraspecific variation; leaf life span; nitrogen supply; nutrient resorption; secondary succession; sensitivity analysis.

\section{INTRODUCTION}

Nutrient economy is an important determinant of plant performance (Chapin 1980, Grime 2001). The concept of nutrient use efficiency, NUE (defined as the ratio between the biomass produced by, and the flux of nutrient through, a system over a given period of time; Garnier and Aronson [1998]), was introduced to describe species variation in resource use and its dependence on soil nutrient availability (Chapin 1980, Vitousek 1982, Garnier and Aronson 1998). NUE can be split into two components, namely nutrient productivity (i.e., dry-matter productivity per unit nutrient) and mean residence time (MRT) of the nutrient in question (Berendse and Aerts 1987). Nutrient conservation is thought to depend on a prolonged MRT (Aerts and De Caluwe 1995, Eckstein and Karlsson 1997, Vásquez de Aldana and Berendse 1997, Berendse 1998, Garnier and

Manuscript received 8 August 2006; revised 8 December 2006; accepted 22 December 2006. Corresponding Editor: M. A. Arthur.

${ }^{3}$ Present address: University of the Aegean, Department of Environment, Biodiversity Management Laboratory, Building Xenia, University Hill, 81100 Mytilene, Lesvos, Greece. E-mail: ekazakou2001@yahoo.com
Aronson 1998). Garnier and Aronson (1998) proposed to express MRT as follows:

$$
\mathrm{MRT}=\left(\frac{1}{1-\mathrm{RE}}\right)\left(\frac{1}{\mathrm{BL}}\right) .
$$

According to Eq. 1, MRT depends on nutrient resorption efficiency, RE (the amount of nutrients resorbed during senescence, calculated as the proportion of the amount of nutrients in the leaves prior to senescence; Aerts [1996]), and on the relative biomass loss rate, $\mathrm{BL}$ (which is calculated as the biomass lost over one year divided by the mean annual biomass). Assuming that $\mathrm{BL}$ is inversely related to the mean biomass life span (Garnier and Aronson 1998), the MRT of the leaf can be estimated using the following equation:

$$
\mathrm{MRT}=\frac{\mathrm{LLS}}{1-\mathrm{RE}}
$$

where LLS is the leaf life span. Despite the simplicity of Eq. 2, the relative importance of each of its components in explaining variation among and between species in MRT is not straightforward.

The first aim of the present study is to test the relative contribution of LLS and RE to MRT, which has seldom 
been done (see Escudero et al. 1992, Eckstein et al. 1999). In the first study (Escudero et al. 1992), it was suggested that the effect of leaf longevity on MRT was much stronger than that of resorption, whereas results from the second one (Eckstein et al. 1999) yielded different conclusions depending on the level of comparison. Using Eq. 2, Eckstein et al. (1999) varied each component of MRT in turn, while the other was held constant. Based on this analysis and using empirical data compiled from the literature, Eckstein et al. (1999) concluded that LLS contributes more than RE to interspecific differences, whereas RE seems to be relatively more important at the intraspecific level.

Although the numerical approach proposed by Eckstein et al. (1999) is valuable, we argue that a more analytical approach can be fruitfully employed to assess the relative influence of LLS and RE upon MRT. We introduce the use of the elasticity analysis method (de Kroon et al. 1986, 2000, Caswell 2001), which, in this particular context, aims at measuring the impact on MRT of a small change in one component relative to the impact of an equal change in the other element. One major advantage of this approach is that, instead of deriving conclusions for particular values of LLS and RE, the elasticity analysis allows the impact of these factors on MRT to be formally identified and quantified. Technically, this is achieved by computing the first derivatives of MRT with respect to each parameter. This analytical tool has proved useful in population ecology to assess the relative contribution of demographic parameters to population growth rate (Caswell 2001), and in ecological economics to measure the responsiveness of a change in supply to a change in demand (Daly and Farley 2004). One limitation of a simple elasticity analysis is that it solely focuses on the relative effect of the variables on the MRT, although the influence of LLS may differ depending on RE and vice versa. Therefore, we also quantified the joint effect of LLS and $\mathrm{RE}$ on MRT, which required the calculation of the second derivatives of MRT with respect to LLS and RE (Caswell 1996).

Eckstein et al. (1999) suggested that there is a strong need for further research regarding the processes of nutrient conservation, particularly with respect to intraspecific variation. The principal reason for this is that most data used in their compilation did not allow inter- and intraspecific variation of LLS and RE to be tested on the same species. Additionally, in many studies, comparisons of LLS or RE have been conducted among species growing in differing habitats (Aerts 1996). The second aim of this study, therefore, is to test the effects of variation of LLS and nitrogen RE on MRT at the intraspecific level, in addition to the interspecific one.

In this paper, we first apply the elasticity analysis to Eq. 2, and we then use data from 18 species grown in a common garden experiment at two levels of nitrogen supply as a case study, to analyze how LLS and RE affect MRT not only at the interspecific level, but also at the intraspecific level in response to nitrogen availability.

\section{Methods \\ Calculating the first derivatives of $M R T$}

We calculated the first derivatives of MRT in Eq. 2 with regard to LLS and RE in turn. However, because Eq. 2 combines two parameters that were not measured on the same scale, we resorted to the proportional effect on MRT of proportional changes of LLS and RE, usually referred to as elasticity (de Kroon et al. 1986, 2000). Elasticity has an appealing interpretation as giving the contribution of the corresponding parameter to the rate of change in MRT.

We first calculated the elasticity of MRT with respect to LLS, denoted $e_{\text {LLS }}$. This can be formulated as

$$
e_{\mathrm{LLS}}=\left(\frac{\mathrm{LLS}}{\mathrm{MRT}}\right)\left(\frac{\partial \mathrm{MRT}}{\partial \mathrm{LLS}}\right)=\left(\frac{\mathrm{LLS}}{\frac{\mathrm{LLS}}{1-\mathrm{RE}}}\right)\left(\frac{1}{1-\mathrm{RE}}\right)=1
$$

We then calculated the elasticity of MRT to changes in $\mathrm{RE}$ denoted $e_{\mathrm{RE}}$. This is given by

$$
\begin{aligned}
e_{\mathrm{RE}} & =\left(\frac{\mathrm{RE}}{\mathrm{MRT}}\right)\left(\frac{\partial \mathrm{MRT}}{\partial \mathrm{RE}}\right)=\left(\frac{\mathrm{RE}}{\frac{\mathrm{LLS}}{1-\mathrm{RE}}}\right)\left(\frac{\mathrm{LLS}}{(1-\mathrm{RE})^{2}}\right) \\
& =\frac{\mathrm{RE}}{1-\mathrm{RE}} .
\end{aligned}
$$

\section{Calculating the second-order derivatives of $M R T$}

A better insight into MRT variation can be gained by calculating the second-order derivatives of MRT, which quantify the changes in elasticity as the values of LLS and RE change simultaneously (Caswell 1996, 2001). The joint contribution of LLS and RE to variation of MRT was assessed by calculating the cross partial derivatives (CPDs): $\partial^{2} \mathrm{MRT} /(\partial \mathrm{RE} \partial \mathrm{LLS})$ and $\partial^{2} \mathrm{MRT} /(\partial \mathrm{LLS} \partial \mathrm{RE})$. Interestingly, they were found to be equal and to depend solely on RE, which greatly facilitates the biological interpretation:

$$
\begin{gathered}
\frac{\partial^{2} \mathrm{MRT}}{\partial \mathrm{RE} \partial \mathrm{LLS}}=\frac{\partial^{2} \mathrm{MRT}}{\partial \mathrm{LLS} \partial \mathrm{RE}}=\frac{1}{(1-\mathrm{RE})^{2}} . \\
\text { MATERIALS } \\
\text { Study site, species, and experimental design }
\end{gathered}
$$

The experiment was conducted in the experimental garden of the Centre d'Ecologie Fonctionnelle et Evolutive (CEFE), Centre National de la Recherche Scientifique (CNRS) located in Montpellier, France $\left(43^{\circ} 59^{\prime} \mathrm{N}, 3^{\circ} 51^{\prime} \mathrm{E}\right)$. The altitude is $60 \mathrm{~m}$ above sea level. 
The climate is Mediterranean subhumid (Daget 1977) with cool-to-cold winters and marked summer drought. Between January and December 2004, the mean annual rainfall was $659 \mathrm{~mm}$ and the mean monthly temperature was $14.5^{\circ} \mathrm{C}$ (data from CEFE meteorological station).

Eighteen species were selected among the most abundant species occurring in plant communities from a Mediterranean old-field succession of southern France, based on knowledge about their usual position in French Mediterranean old-field successions (Escarré et al. 1983, Navas et al. 2003, Garnier et al. 2004). Three main stages were recognized based on the time since vineyard abandonment: early ( $0-6$ years); intermediate ( $7-15$ years); and advanced (15-45 years). Six species were chosen for each of the three successional stages.

During the summer of 2003, seeds or ramets (according to species) were collected in the field sites described by Garnier et al. (2004) or Navas et al. (2003). Each species was cultivated as a monoculture in the common garden $(1.20 \times 1.20 \mathrm{~m}$ plots $)$, where the soil (calcic cambisol; FAO 1974) is comparable to that found in the old-field successions ( $\mathrm{pH} 7.82$; mean initial nitrogen concentration $1.38 \mathrm{mg} \mathrm{N} / \mathrm{g}$ ). Monocultures of each species were established in October and November 2003 by transplantation of either seedlings or ramets, in order to ensure a standard plant density $\left(100\right.$ plants $\left./ \mathrm{m}^{2}\right)$. Species monocultures were replicated four times within two levels of nitrogen supply: the limiting treatment $(\mathrm{N}-)$ was the natural soil of the experimental garden; in the non-limiting treatment $(\mathrm{N}+), 250 \mathrm{~kg} / \mathrm{ha}$ of nitrogen in the form of ammonium nitrate was applied to ensure a non-limiting nitrogen level for all species (for further details, see Kazakou et al. 2007).

\section{Leaf life span and nitrogen resorption measurements}

For all species, leaf life span was measured on 12 different healthy individuals per species and nitrogen level (three individuals per plot). At first census on 23 February 2004, a well-lit stem (or sheath) was selected and marked with a colored ring or twine. The last mature leaf of that stem was marked with ink and then monitored twice a week in order to record the date when the following leaf appeared. This new leaf was marked and monitored every week until senescence. A leaf was considered to be dead when it had turned completely brown or had fallen. In total, 864 leaves were monitored during the period from February to September 2004. The leaf life span (LLS) was defined as the difference between the date of leaf death and the date of leaf birth, and the mean by treatment was calculated.

Nitrogen and phosphorus resorption efficiencies (RE) were calculated as the proportional decrease in nutrient (nitrogen and phosphorus, respectively) content between live and dead leaves, standardized by their leaf size before senescence and by accounting for leaf mass loss

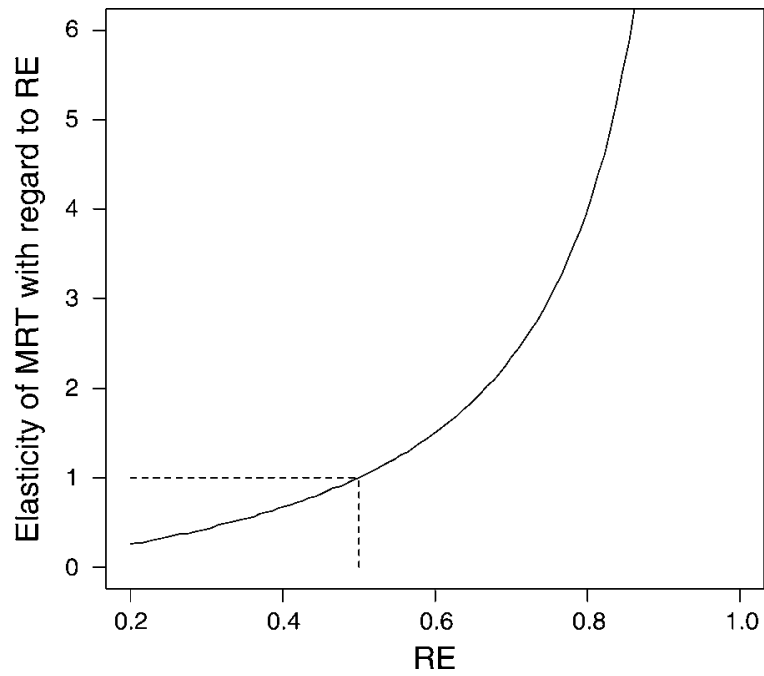

FIG. 1. Mean residence time (MRT) elasticity with regard to changes in nitrogen resorption efficiency (RE) based on Eq. 4 (solid line). As an example, the elasticity of MRT is displayed for $\mathrm{RE}=0.5$ (dashed line).

during senescence. For a complete description of methods, see Kazakou et al. (2007).

\section{Data analysis}

Using the species within each plot, we tested the distribution of both variables (leaf life span and nitrogen RE) for non-normality (Shapiro-Wilk test, $\alpha=0.05$ ) and log-transformed when necessary. The effects of stage and treatment were tested using a two-way ANOVA. Statistical analyses were performed with SAS Version 8 (SAS Institute 2001).

\section{Results}

\section{Elasticity of MRT to changes in LLS and RE}

We investigated the relative influence of LLS and nitrogen RE on MRT by addressing the question: "How would a plant increase its MRT most: by increasing its LLS or its RE?" To answer this, we studied sensitivities by assessing how MRT was influenced by a small change in LLS or RE, holding the other one constant (Caswell 2001).

Eq. 3 indicates that the elasticity of MRT to changes in LLS varies linearly, with a slope equal to 1 . This means that a change of $10 \%$ in LLS will therefore induce a change of $10 \% \times 1=10 \%$ in MRT.

According to Eq. 4, the relative effect of RE upon the elasticity of MRT increases exponentially (Fig. 1, solid line): when RE is low (around 0.5), $e_{\mathrm{RE}}$ varies linearly with resorption. For example, if RE equals 0.5 , elasticity is 1 and a change of $10 \%$ in $\mathrm{RE}$ will induce a change of $10 \% \times 1=10 \%$ in MRT (Fig. 1, dotted line). If RE is higher than 0.5 , the relative contribution of RE to variations in MRT becomes more important. For example, if RE equals 0.8 , elasticity is 4 and a change 


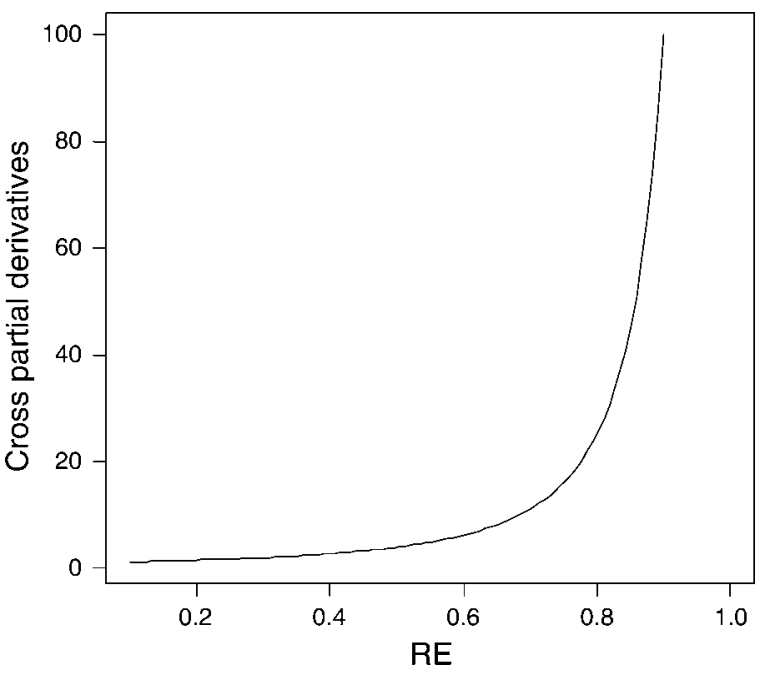

FIG. 2. Variation of the cross partial derivatives depending on nitrogen resorption efficiency (RE) according to Eq. 5.

of $10 \%$ in RE yields a change of $10 \% \times 4=40 \%$ in MRT. This result emphasizes the high contribution of $\mathrm{RE}$ to MRT for species with high resorption efficiencies.

Joint contribution of LLS and RE to variation of MRT

The cross partial derivatives (CPDs) are plotted in Fig. 2 with respect to RE. If RE is less than 0.5 , the CPDs values are close to 0 , meaning that an increase in LLS does not increase the sensitivity of MRT to RE. Because the CPDs are equal, the reverse statement also holds; that is, an increase in RE does not increase the sensitivity of MRT to LLS. If RE is greater than 0.5 , the CPDs values increase greatly, showing that an increase in LLS substantially increases the sensitivity of MRT to RE. Similarly, an increase in RE increases the sensitivity of MRT to LLS.

\section{Applications to Our Data Set}

\section{Elasticity of MRT to changes in LLS and RE}

At the interspecific level, our data set reveals that LLS ranged from 45 (Geranium rotundifolium) to 112 days (Rubia peregrina) in the $\mathrm{N}-$ treatment. ANOVA analyses showed a significant increase in LLS with the successional stage $\left(F_{1,2}=203.43, P<0.0001\right)$ : LLS of species from advanced succession in the $\mathrm{N}-$ treatment was $30 \%$ (and $32 \%$ in the $\mathrm{N}+$ treatment) higher than that of species from early and intermediate succession. As a consequence, according to Eq. 3, the observed increase in LLS with species' successional stage causes an increase of MRT by up to $30 \%$. In the case of intraspecific variation, the fertilization treatment had a negative effect on LLS, with an average decrease of $13 \%$ in $\operatorname{LLS}\left(F_{1,2}=82.58, P<0.0001\right)$. Such a decrease in LLS leads to a proportional $13 \%$ decrease in MRT with the fertilization treatment.
The studied species exhibit high values of both nitrogen and phosphorus RE, around 0.7 (but see Veronica persica and Geranium rotundifolium, for which $\mathrm{RE}=0.5$ ). These high values of RE are partly the consequence of substantial mass loss during senescence (23-55\% of initial leaf mass; Kazakou et al. 2007), which has a significant weight in the calculation of RE. Both nitrogen and phosphorus RE were significantly higher (by $27 \%$ and $22 \%$, respectively) when mass loss was taken into account $\left(F_{\mathrm{N}-}(\right.$ for $\mathrm{N})=9.63, P<0.01 ; F_{\mathrm{N}+}$ $($ for $\mathrm{N})=8.34, P<0.01 ; F_{\mathrm{N}-}($ for $\mathrm{P})=11.46, P<0.01$; $F_{\mathrm{N}+}($ for $\mathrm{P})=4.99, P<0.05$; for all tests, $\left.\mathrm{df}=1,2\right)$, as compared to a calculation based on nutrient concentrations (data from Kazakou et al. 2007).

Combined with Eq. 3 and Fig. 1, the observed patterns showed that $\mathrm{RE}$ has a strong influence on MRT variation. At the interspecific level, nitrogen RE increases significantly with the successional stage by up to $12 \%$, on average, in the $\mathrm{N}-$ treatment: species from intermediate and advanced successional stages resorb more $\mathrm{N}$ than species from early stages $\left(F_{1,2}=12.09, P<\right.$ 0.0001). At the intraspecific level, nitrogen RE did not show a clear response to fertilization treatment $\left(F_{1,2}=\right.$ $1.11, P=0.30)$, so the elasticity of MRT could not be associated with changes in RE. Phosphorus RE increased significantly $\left(F_{1,2}=16.22, P<0.001\right)$ by $8 \%$ in the $\mathrm{N}+$ treatment, leading to a $4 \%$ increase of phosphorus MRT. Therefore, LLS and phosphorus RE did not vary in the same direction in response to nitrogen application: fertilization causes a decrease in LLS and an increase in phosphorus RE. The response of MRT to the fertilization treatment will therefore be defined by the joint contribution of LLS and RE.

\section{Joint contribution of LLS and RE to variation of MRT}

By calculating the joint contribution of LLS and RE to variation of MRT, we address two questions. First, do changes in RE values change MRT's sensitivity to LLS? Because LLS increases with species' successional stage $\left(F_{1,2}=203.43, P<0.0001\right)$, the elasticity analysis showed that a $30 \%$ increase in LLS results in a $42 \%$ increase of MRT (as previously mentioned). Consequently, RE values being greater than 0.5 for all species (except $V$. persica and $G$. rotundifolium), an increase in RE with the successional stage increases the sensitivity to LLS (Fig. 2). More precisely, when species resorb more than $50 \%$ of their nutrients, the increase in nitrogen RE by $12 \%$, combined with the observed $30 \%$ increase in LLS with species' successional stage, causes an increase of much more than $30 \%$ in MRT. On the other hand, although LLS decreases along with the fertilization by $13 \%$, inducing a $13 \%$ decrease in MRT, nitrogen RE was not affected by the fertilization, so we did not attempt to relate the sensitivity of MRT to LLS. However, phosphorus RE increased by $8 \%$ with 
TABLE 1. Leaf life span (LLS), and nitrogen and phosphorus resorption efficiency (RE), by successional stage, for two levels of nitrogen supply.

\begin{tabular}{|c|c|c|c|c|c|c|}
\hline \multirow{2}{*}{$\begin{array}{l}\text { Successional } \\
\text { stage }\end{array}$} & \multicolumn{2}{|c|}{ LLS (days) } & \multicolumn{2}{|c|}{ Nitrogen RE } & \multicolumn{2}{|c|}{ Phosphorus RE } \\
\hline & $\mathrm{N}-$ & $\mathrm{N}+$ & $\mathrm{N}-$ & $\mathrm{N}+$ & $\mathrm{N}-$ & $\mathrm{N}+$ \\
\hline \multicolumn{7}{|l|}{ Early } \\
\hline $\begin{array}{l}\text { Range } \\
\text { Mean }\end{array}$ & $\begin{array}{c}45.06-70.63 \\
62.82\end{array}$ & $\begin{array}{c}35.88-68.60 \\
56.57\end{array}$ & $\begin{array}{c}0.46-0.81 \\
0.66\end{array}$ & $\begin{array}{c}0.40-0.77 \\
0.64\end{array}$ & $\begin{array}{c}0.42-0.79 \\
0.59\end{array}$ & $\begin{array}{c}0.40-0.79 \\
0.59\end{array}$ \\
\hline \multicolumn{7}{|l|}{ Intermediate } \\
\hline $\begin{array}{l}\text { Range } \\
\text { Mean }\end{array}$ & $\begin{array}{c}54.67-76.70 \\
64.34\end{array}$ & $\begin{array}{c}43.57-59.09 \\
51.47\end{array}$ & $\begin{array}{c}0.56-0.88 \\
0.75\end{array}$ & $\begin{array}{c}0.72-0.86 \\
0.80\end{array}$ & $\begin{array}{c}0.46-0.77 \\
0.66\end{array}$ & $\begin{array}{c}0.67-0.86 \\
0.80\end{array}$ \\
\hline \multicolumn{7}{|l|}{ Advanced } \\
\hline $\begin{array}{l}\text { Range } \\
\text { Mean }\end{array}$ & $\begin{array}{c}66.86-112 \\
90.23\end{array}$ & $\begin{array}{c}58.67-89.50 \\
79.73\end{array}$ & $\begin{array}{c}0.63-0.87 \\
0.80\end{array}$ & $\begin{array}{c}0.58-0.89 \\
0.70\end{array}$ & $\begin{array}{c}0.61-0.83 \\
0.79\end{array}$ & $\begin{array}{c}0.71-0.92 \\
0.80\end{array}$ \\
\hline
\end{tabular}

Notes: Leaf life span (LLS) was defined as the difference between the date of leaf death and the date of leaf birth. Resorption efficiency is the amount of nutrients resorbed during senescence, calculated as the proportion of the nutrients in the leaves prior to senescence. The limiting treatment $(\mathrm{N}-)$ was the natural soil of the experimental garden; in the non-limiting treatment $(\mathrm{N}+)$, 250 $\mathrm{kg} / \mathrm{ha}$ of nitrogen in the form of ammonium nitrate was applied. Data are from Kazakou et al. (2007).

increased $\mathrm{N}$ supply, which would induce an increase in MRT (according to Eq. 5), even though LLS decreased.

Second, do changes in LLS influence MRT's sensitivity to RE? Regarding the sensitivity to RE, the $12 \%$ increase of nitrogen RE with species' successional stage causes an average $36 \%$ increase in MRT's elasticity. Because LLS was also found to increase with the successional stage, and the mean RE value being equal to 0.75 (Table 1), this increase results in a much more than $36 \%$ increase of MRT.

\section{Discussion}

\section{Relative contribution of LLS and RE on the MRT at the interspecific level}

In our study, LLS increased significantly with species' successional status and thus led to a proportional increase in MRT. This result is in accordance with previous studies along successional gradients. Navas et al. (2003) demonstrated that the LLS of 42 species from a Mediterranean old-field succession increased with species' successional status. The same trend was shown with nitrogen RE: species from advanced succession tend to resorb their nutrients more efficiently than species from earlier stages.

As a result, during the studied succession, species tend to increase their MRT by a $30 \%$ average increase in LLS (in the $\mathrm{N}-$ treatment) and a $12 \%$ average increase in nitrogen RE. This increase thus produces an exponential increase in MRT. More precisely, if RE equals $0.75, \mathrm{e}_{\mathrm{RE}}$ $=0.75 /(1-0.75)=3$, with an increase of $12 \% \times 3=36 \%$ in MRT. Phosphorus RE of species from advanced succession was $15 \%$ higher than RE of species from early and intermediate succession. This increase will lead to a $15 \% \times 3=45 \%$ increase of phosphorus MRT with species' successional status. However, as most of the species in our study have RE greater than 0.5 , the joint contribution of LLS and RE on MRT is substantial and the $12 \%$ increase of RE with species' successional status induces a more than $36 \%$ increase in MRT. The same result was found with phosphorus RE.

Eckstein et al. (1999) concluded that RE is relatively more important in explaining variation in MRT at the intraspecific level than at the interspecific level. The elasticity analysis formally demonstrated that, for species resorbing their nutrients very efficiently, RE is a key factor in variation of MRT at the interspecific level. Data from the literature (compiled from Eckstein et al. [1999]) showed that woody deciduous and herb species have $\mathrm{RE}>0.5$ (0.54 and 0.59 , respectively), whereas a RE of woody evergreen and graminoid is close to 0.5 ( 0.5 and 0.41 , respectively). Due to the high values of RE and according to Eqs. 3 and 4, the relative importance of RE in determining MRT is considerable for all of the growth forms.

\section{Relative contribution of LLS and RE on the MRT at the intraspecific level}

We hypothesized that species' nutrient conservation strategies would be affected by soil $\mathrm{N}$ availability. This hypothesis was confirmed in part: LLS decreased in the $\mathrm{N}+$ treatment, but nitrogen RE was not significantly affected. This clear phenotypic response of LLS to nutrient availability is consistent with previous studies (Shaver 1981, Shaver and Melillo 1984; but see Aerts and de Caluwe 1995). Van Heerwaarden et al. (2003) found nutrient RE decreases with increasing nutrient supply. Our results are in agreement with Aerts and Chapin (2000), who indicate that although nitrogen RE is an important nutrient conservation mechanism, it does not explain the distribution of species over habitats differing in soil nitrogen fertility. In our study, the decrease in MRT with the fertilization treatment is therefore mostly due to the decrease in LLS.

By contrast, in the $\mathrm{N}+$ treatment (soil nitrogen nonlimiting for plant growth), when soil phosphorus became 
limiting for growth (data not shown), phosphorus RE increased even though LLS decreased. The elasticity analysis allowed us to determine the relative importance of LLS and phosphorus RE in assessing the variation in phosphorus MRT. More precisely, given the importance of RE, MRT keeps increasing with RE despite the decrease in LLS.

Considering other data sets (see Eckstein et al. 1999), graminoid and woody species present the higher intraspecific variation in nitrogen RE. Because these species have high RE (41.4\% and 54\%, respectively), these variations affect MRT (see Eq. 4). With regard to the joint contribution of LLS and RE to MRT, we conclude that changes in RE affect the sensitivity of MRT to LLS. Even though RE did not vary at the intraspecific level for our data set, the relative contribution of RE on MRT should not be underestimated.

\section{Elasticity as a tool to assess variation in MRT}

Eckstein et al. (1999) graphically assessed the effect of changes on LLS or RE on MRT by keeping constant one variable and varying the other. Our study proposed a novel approach for estimating the relative contribution of LLS and RE to MRT. The originality lies in that it provides a numerical estimation of the contribution of each variable on MRT, based on Eq. 1. As a consequence, Eqs. 3 and 4 can also be applied to any other data sets and therefore may be helpful in predicting the effects of changes on LLS or RE on MRT. The elasticity analysis relies on the calculation of first derivatives and focuses on the relative effect on MRT of one variable while the other is kept constant. In this note, we have focused on the effect on the response variable MRT of small relative changes of mean values of LLS and RE. If needed, sensitivities can still be calculated to evaluate absolute contributions by simply ignoring the rescaling term in Eqs. 3 and 4 . It is noteworthy that elasticities are also likely to be affected by the variability in those two variables. However, elasticities in this context are much more complex to derive analytically (Haridas and Tuljapurkar 2005), and this is the object of ongoing work. A promising alternative could be the use of resampling methods (Caswell et al. 1998). For the sake of biological realism, one should bear in mind that the two variables may covary and the influence of LLS may differ depending on RE, and vice versa. Therefore, we also proposed to quantify the joint effect of LLS and RE on MRT by calculating the second derivates (Caswell 1996). To our knowledge, this is the first attempt in functional ecology to use first and second derivatives in order to assess the sensitivity of a function.

The prerequisite to the use of Eq. 2 is that variation in MRT is mainly explained by LLS and RE. Although MRT has been shown to be formally related to RE (Garnier and Aronson 1998; see also Eq. 1), it is almost impossible to estimate the whole-plant RE. First, Garnier and Aronson (1998) assume that mass losses during senescence may be insignificant. However, leaves of herbaceous species can lose more than $50 \%$ of their mass during senescence (Vernescu et al. 2005; for the species of the present study, see Kazakou et al. [2007]). We therefore took leaf mass loss during senescence into account to estimate nitrogen RE (see also Güsewell 2005). Secondly, in order to estimate whole-plant MRT, the roots, shoots, and reproductive organs of the plant should be taken into account as well. In such a case, Eq. 2 would depend on more than two parameters and the graphical procedure advocated by Eckstein et al. (1999) would become intractable. Interestingly, the elasticity analysis does not suffer from this issue, and is routinely used in population dynamics studies in which species population growth rates can depend upon numerous demographic transitions (Caswell 2001). Finally, we see important evolutionary aspects in the use of elasticity analyses, because they would allow us to identify the critical traits that determine plant fitness through control of nutrient MRT in situations in which nutrients are limiting. In particular, we have demonstrated that, at high values of RE, this trait becomes of paramount importance as a determinant of plant fitness, which has been previously underestimated.

We therefore anticipate that elasticity analyses, using both first and second derivatives, will become an essential tool to assess the relative contribution of several variables on a target variable in functional ecology.

\section{ACKNOWLEDGMENTS}

E. Kazakou was financially supported by the EU project VISTA (Vulnerability of Ecosystem Services to Land Use Change in Traditional Agricultural Landscapes) (contract no. EVK2-2001-15 0003). O. Gimenez's research was supported by a Marie-Curie Intra-European Fellowship within the Sixth European Community Framework Programme. Thanks to C. Roumet, M.-L. Navas, C. Violle, G. Laurent, A. Blanchard, and C. Collin for all the help in the field, B. Buatois for the nitrogen elemental analysis, and J.-D. Lebreton for elements of bibliography. Two anonymous referees provided helpful comments on a previous version of the manuscript. This is a publication from the GDR 2574 "Utiliterres" (CNRS, France).

\section{Literature Cited}

Aerts, R. 1996. Nutrient resorption from senescing leaves of perennials: are there general patterns? Journal of Ecology 84: 597-608.

Aerts, R., and F. S. Chapin. 2000. The mineral nutrition of wild plants revisited: A re-evaluation of processes and patterns. Advances in Ecological Research 30:1-67.

Aerts, R., and H. de Caluwe. 1995. Interspecific and intraspecific differences in shoot and leaf life-span of 4 Carex species which differ in maximum dry-matter production. Oecologia 102:467-477.

Berendse, F. 1998. Effects of dominant plant species on soils during succession in nutrient-poor ecosystems. Biogeochemistry 42:73-88. 
Berendse, F., and R. Aerts. 1987. Nitrogen-use efficiency: a biological meaningful definition? Functional Ecology 1:293296.

Caswell, H. 1996. Second derivatives of population growth rate: calculation and applications. Ecology 77:870-879.

Caswell, H. 2001. Matrix population models: construction, analysis, and interpretation. Sinauer Associates, Sunderland, Massachusetts, USA.

Caswell, H., S. Brault, A. Read, and T. Smith. 1998. Harbor porpoise and fisheries: an uncertainty analysis of incidental mortality. Ecological Applications 8:1226-1238.

Chapin, F. S. 1980. The mineral nutrition of wild plants. Annual Review of Ecology and Systematics 11:233-260.

Daget, P. 1977. Le bioclimat méditerranéen: caractères généraux et modes de caractérisation. Vegetatio 34:1-20.

Daly, H. E., and J. Farley. 2004. Ecological economics: principles and applications. Island Press, Washington, D.C., USA.

De Kroon, H., A. Plaisier, J. van Groenendael, and H. Caswell. 1986. Elasticity: the relative contribution of demographic parameters to population growth rate. Ecology 67:14271431.

De Kroon, H., J. van Groenendael, and J. Ehrlén. 2000. Elasticities: a review of methods and model limitations. Ecology 81:607-618.

Eckstein, R. L., and P. S. Karlsson. 1997. Above-ground growth and nutrient use by plants in a subarctic environment: effects of habitats, life-form and species. Oikos 79:311-324.

Eckstein, R. L., P. S. Karlsson, and M. Weih. 1999. Leaf life span and nutrient resorption as determinants of plant nutrient conservation in temperate-arctic regions. New Phytologist 143:177-189.

Escarré, J., C. Houssard, M. Debussche, and J. Lepart. 1983. Evolution de la végétation et du sol après abandon cultural en région méditerranéenne: étude de succession dans les Garrigues du Montpelliérains (France). Acta Oecologica 4: 221-239.

Escudero, A., J. M. del Arco, I. C. Sanz, and J. Ayala. 1992. Effects of leaf longevity and retranslocation efficiency on the retention time of nutrients. Oecologia 90:80-87.

FAO (United Nations Food and Agriculture Organization). 1974. Soil map of the world. Volume 1. Legend. UNESCO, Paris, France.

Garnier, E., and J. Aronson. 1998. Nitrogen-use efficiency from leaf to stand level: clarifying the concept. Pages 515-538 in $\mathrm{H}$. Lambers, H. Poorter, and M. M. I. Van Vuuren, editors.
Inherent variation in plant growth. Physiological mechanisms and ecological consequences. Backhys Publishers, Leiden, The Netherlands.

Garnier, E., J. Cortez, G. Billès, M.-L. Navas, C. Roumet, M. Debussche, G. Laurent, A. Blanchard, D. Aubry, A. Bellmann, C. Neill, and J.-P. Toussaint. 2004. Plant functional markers capture ecosystem properties during secondary succession. Ecology 85:2630-2637.

Grime, J. P. 2001. Plant strategies, vegetation processes and ecosystem properties. John Wiley, Chichester, UK.

Güsewell, S. 2005. Nutrient resorption of wetland graminoids is related to the type of nutrient limitation. Functional Ecology 19:344-354.

Haridas, C. V., and S. Tuljapurkar. 2005. Elasticities in variable environments: properties and implications. American Naturalist 166:481-495.

Kazakou, E., E. Garnier, M.-L. Navas, C. Roumet, C. Collin, and G. Laurent. 2007. Components of nutrient residence time and the leaf economics spectrum in species from Mediterranean old-fields differing in successional status. Functional Ecology 21:235-245.

Navas, M.-L., B. Ducout, C. Roumet, J. Richarte, J. Garnier, and E. Garnier. 2003. Leaf life span, dynamics and construction cost of species from Mediterranean old-fields differing in successional status. New Phytologist 153:213228.

SAS Institute. 2001. SAS Version 8. SAS Institute, Cary, North Carolina, USA.

Shaver, G. 1981. Mineral-nutrition and leaf longevity in an evergreen shrub, Ledum palustre ssp. decumbens. Oecologia 49:362-365.

Shaver, G., and J. Melillo. 1984. Nutrient budgets of marsh plants: efficiency concepts and relation to availability. Ecology 65:1491-1510.

Van Heerwaarden, L. M., S. Toet, and R. Aerts. 2003. Current measures of nutrient resorption efficiency lead to a substantial underestimation of real resorption efficiency: facts and solutions. Oikos 101:664-669.

Vásquez de Aldana, B. R., and F. Berendse. 1997. Nutrient-use efficiency in six perennial grasses from contrasting habitats. Functional Ecology 11:619-626.

Vernescu, C., J. Coulas, and P. Ryser. 2005. Leaf mass loss in wetland graminoids during senescence. Oikos 109:187-195.

Vitousek, P. 1982. Nutrient cycling and nutrient use efficiency. American Naturalist 119:553-572. 